\title{
Antidiabetic activities of a cucurbitane-type triterpenoid compound from Momordica charantia in alloxan-induced diabetic mice
}

\author{
BOWEN JIANG $^{1 *}$, MINGLI JI ${ }^{2 *}$, WEI LIU ${ }^{1}$, LILI CHEN ${ }^{1}$, ZHIYU CAI $^{1}$, YUQING ZHAO $^{3,4}$ and XIULI BI ${ }^{1}$ \\ ${ }^{1}$ College of Life Science, Liaoning University, Shenyang, Liaoning 110036; \\ ${ }^{2}$ Department of Physiology, College of Basic Medicine, Xinxiang Medical University, \\ Xinxiang, Henan 453003; ${ }^{3}$ Department of Traditional Chinese Medicine; \\ ${ }^{4}$ Key Laboratory of Structure-Based Drug Design and Discovery of Ministry of Education, \\ Shenyang Pharmaceutical University, Shenyang, Liaoning 110016, P.R. China
}

Received September 3, 2015; Accepted September 12, 2016

DOI: $10.3892 / \mathrm{mmr} .2016 .5800$

\begin{abstract}
Momordica charantia has been used to treat a variety of diseases, including inflammation, diabetes and cancer. A cucurbitane-type triterpenoid [(19R,23E) $-5 \beta$, 19-epoxy-19-methoxy-cucurbita-6,23,25-trien-3 $\beta$-o-1] previously isolated from $M$. charantia was demonstrated to possess significant cytotoxicity against cancer cells. The current study investigated the effects of this compound (referred to as compound K16) on diabetes using an alloxan-induced diabetic mouse model. C57BL/6J mice were intraperitoneally injected with alloxan $(10 \mathrm{mg} / \mathrm{kg}$ body weight), and those with blood glucose concentration higher than $10 \mathrm{mM}$ were selected for further experiments. Diabetic C57BL/6J mice induced by alloxan were administered $0.9 \%$ saline solution, metformine (10 mg/kg body weight), or K16 (25 or $50 \mathrm{mg} / \mathrm{kg}$ body weight) by gavage for 4 weeks, followed by analysis of blood glucose level, glucose tolerance, serum lipid levels and organ indexes. The results demonstrated that compound K16 significantly reduced blood glucose $(31-48.6 \%)$ and blood lipids (13.5-42.8\%; triglycerides and cholesterol), while improving glucose tolerance compared with diabetic mice treated with
\end{abstract}

Correspondence to: Professor Xiuli Bi, College of Life Science, Liaoning University, 66 Chongshan Road, Shenyang, Liaoning 110036 , P.R. China

E-mail: xiulibi@gmail.com; xiulibi@lnu.edu.cn

Professor Yuqing Zhao, Department of Traditional Chinese Medicine, Shenyang Pharmaceutical University, 103 Wenhua Road, Shenyang, Liaoning 110016, P.R. China

E-mail: zyq4885@126.com

*Contributed equally

Key words: alloxan-induced diabetic mouse model, antidiabetic activity, insulin signaling pathway, Momordica charantia, triterpenoid saline solution, suggesting a positive improvement in glucose and lipid metabolism following K16 treatment. Furthermore, similarly to metformine, compound K16 markedly upregulated the expression of a number of insulin signaling pathway-associated proteins, including insulin receptor, insulin receptor substrate 1 , glycogen synthase kinase $3 \beta$, Akt serine/threonine kinase, and the transcript levels of glucose transporter type 4 and AMP-activated protein kinase $\alpha 1$. The results of the current study demonstrated that compound K16 alleviated diabetic metabolic symptoms in alloxan-induced diabetic mice, potentially by affecting genes and proteins involved in insulin metabolism signaling.

\section{Introduction}

Diabetes is one of the most common chronic diseases, which occurs when the pancreas does not produce enough insulin, or when the body cannot effectively use the insulin it produces. The World Health Organization estimates the incidence of diabetes to be $9 \%$ among adults $>18$ years old (1). In 2012 alone, diabetes was the direct cause of 1.5 million mortalities. Of diabetes-associated mortalities, $>80 \%$ occur in low- and middle-income countries (2). There are two types of diabetes: Type 1 diabetes is characterized by a lack of insulin production, whereas Type 2 diabetes is caused by the body's ineffective use of insulin. Both types of diabetes share a common syndrome, which is disordered glucose homeostasis. Disorder in glucose homeostasis is caused by defects in the phosphatidylinositol 3-kinase (PI3K)/Akt serine/threonine kinase (Akt) and AMP-activated protein kinase (Ampk) pathways in insulin-sensitive tissues, which then lead to the accumulation of glucose in the blood. The regulation of glucose uptake is critical for the maintenance of glucose homeostasis. Glucose uptake is dependent on the translocation of glucose transporter type 4 (Glut4) to the plasma membrane. There are two major signaling pathways that regulate the translocation of Glut4. The first is the insulin activated signaling pathway through insulin receptor substrate 1 (IRS1) and PI3K. The second is the insulin-independent signaling pathway activated by 
Ampk. Decreases in insulin-stimulated glucose uptake in the skeletal muscle caused by insulin resistance is a symptom of individuals with Type 2 diabetes (3).

The treatment of diabetes has become a social focus. Existing hypoglycemic drugs, including insulin and other conventional drugs, predominantly aim to relieve the symptoms of a particular type (Type I or II) of diabetes. These drugs may produce certain drug dependencies and side effects. In recent years, interest in using plant extracts as a strategy to prevent or treat diabetes has grown, as they are natural products and are considered to have fewer side effects than conventional treatments. Momordica charantia, commonly termed bitter melon, is one of the popular plants that has been used as medicinal plant for treating diabetes and various other diseases.

M. charantia, a perennial climber, is a tropical and subtropical vine of the family Cucurbitaceae. The fruit, and the whole plant, has been demonstrated to possess antidiabetic, antiviral, ant-bacterial and anticancer activities (4). Extracts of $M$. charantia have been demonstrated to increase cellular glucose uptake by upregulating Glut4 and PI3K, which lead to enhanced cellular insulin signaling pathways (5). Many phytochemicals with hypoglycemic properties have been isolated from the fruit of $M$. charantia, including glycosides (momordin, charantin), alkaloids (momordicin) and polypeptides. These agents have been demonstrated to promote the translocation of glucose transporters and increase the activity of Ampk in insulin resistant animal models $(6,7)$. The protein extract from the fruit pulp of $M$. charantia also stimulates the uptake of glucose into C2C12 myocytes (8).

The compound (19R,23E)-5 $\beta, 19$-epoxy-19-methoxy cucurbita-6,23,25-trien-3 $\beta$-o-1 (compound K16) was previously evaluated for its inhibitory activities toward protein tyrosine phosphatase $1 \mathrm{~B}$, a tyrosine phosphatase that has been implicated as a key target for therapy against Type II diabetes. Additionally, the extraction and identification of two cucurbitane-type triterpenoids from M. charantia were previously reported, and these compound exhibit significant cytotoxicity against cancer cells (9). The present study investigated the antidiabetic activity of compound K16 in alloxan-induced diabetic mice and explored the associated underlying mechanism.

\section{Materials and methods}

Chemical and reagents. 2,4,5,6-Tetraoxypyrimidine (alloxan) was purchased from Sigma-Aldrich (Merck Millipore, Darmstadt, Germany). Metformine was purchased from Shanxi Baozhilin Pharmaceuticals Co., Ltd. (Shanxi, China). Compound K16, a cucurbitane-type triterpenoid isolated from $M$. charantia was provided by Shenyang Pharmaceutical University (Shenyang, China) (10), and its structure is presented in Fig. 1. Antibodies against insulin receptor (IR; cat. no. 3025s; Cell Signaling Technology, Inc., Danvers, MA, USA), and phosphorylated IR (cat. no. 3024s; Cell Signaling Technology, Inc.), IRS1 (phospho-Ser636; cat. no. D120888; Bio Basic Canada, Inc., Markham, ON, Canada), and glycogen synthase kinase $3 \beta$ (GSK3 $\beta$; phospho-Tyr216; cat. no. D155143; Bio Basic Canada, Inc.) were used. Antibody against phosphorylated Akt (cat. no. 13038P) was obtained from Cell Signaling

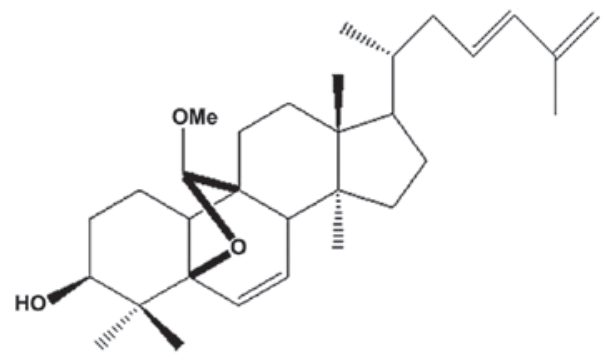

Figure 1. Chemical structure of compound (19R,23E)-5 $\beta, 19$-epoxy-19-methoxy-cucurbita-6,23,25-trien-3 $\beta$-o-10 (K16).

Tachnology, Inc. Antibody against $\alpha$-tubulin (cat. no. Ab102) was purchased from Vazyme (Piscataway, NJ, USA).

Animal care and experimental protocol. Male C57BL/6J mice (5 weeks old; 18-20 g) obtained from Liao Ning Chang Sheng Biotechnology Co., Ltd. (Benxi, China) were maintained in a $12 \mathrm{~h} \mathrm{light/dark} \mathrm{cycle,} \mathrm{and} \mathrm{provided} \mathrm{with} \mathrm{water} \mathrm{and} \mathrm{food}$ ad libitum. The animals were housed in cages maintained at $21 \pm 2.0^{\circ} \mathrm{C}$ with $50 \pm 5 \%$ humidity. The study was approved by the ethics committee of Liaoning Traditional Chinese Medicine University (Shenyang, China).

Establishment of the diabetic mouse model. After 1 week of acclimation, male mice (6 weeks old) were randomly divided into 2 groups: Control group $(n=10)$ and model group $(n=40)$. Mice in the control group mice were administered $0.9 \%$ saline solution, whereas those in the model group received alloxan (50 $\mathrm{mg} / \mathrm{kg}$ body weight). The saline solution and alloxan were administered via intraperitoneal injection, and a total of three injections were given, at $48 \mathrm{~h}$ intervals. Subsequently, blood samples were collected from the tails of the animals and the glucose levels in the blood samples were measured with a glucometer (Roche Diagnostics, Basel, Switzerland). The animals were subjected to a 16 -h fasting period prior to the blood glucose test. Successful establishment of this model was based on mice exhibiting a blood glucose concentration between 10 and $14 \mathrm{mM}$, and exhibiting behavioral changes, including polydipsia, polyphagia and polyuria (11). Only these animals were used in subsequent experiments.

Compound K16 supplementation and sample collection. The alloxan-induced hyperglycemic mice were randomly sorted into 4 groups ( $n=10$ per group), with each group having approximately the equivalent average body weight. One group was administered $0.9 \%$ saline solution (alloxan group). Another group was administered metformin $(10 \mathrm{mg} / \mathrm{kg}$; metformine group) as a positive control as metformin improves insulin resistance. The remaining two groups were each administered compound K16 (25 or $50 \mathrm{mg} / \mathrm{kg}$ body weight). Administration of the drugs was performed by oral gavage, and the treatment lasted for 4 weeks, with three treatments per week. Simultaneously, mice in the control group, (without administration of alloxan) also received $0.9 \%$ saline solution via oral gavage for the equivalent duration and frequency. These mice were considered as healthy control mice. 
A

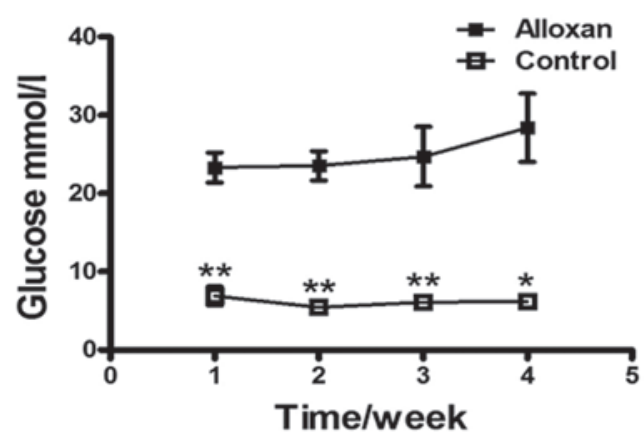

C

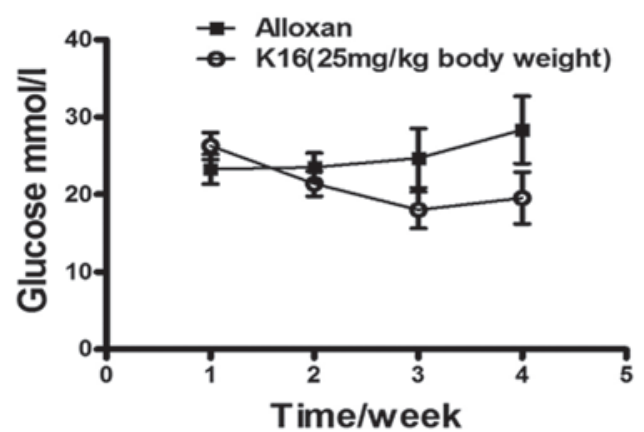

B

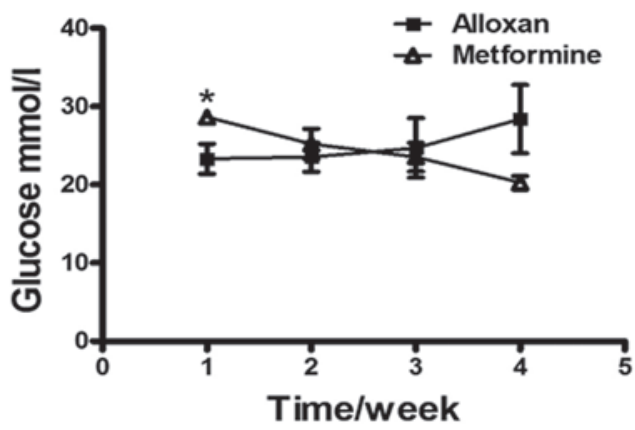

D

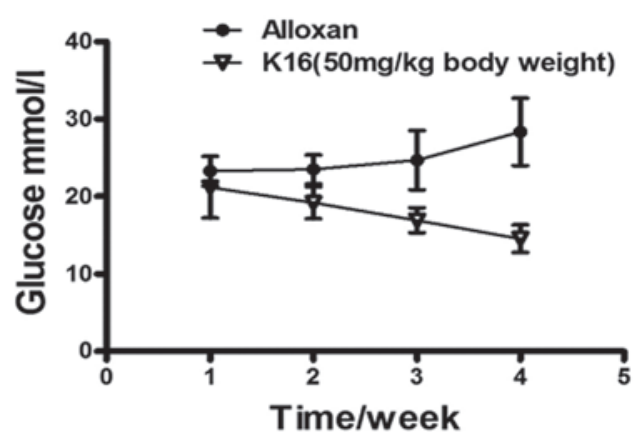

Figure 2. Effects of compound K16 on blood glucose in mice. Mice fasted overnight were used for the experiments. Glucose was measured in (A) control, (B) positive control, (C) mice treated with compound $\mathrm{K} 16$ at the concentration of $25 \mathrm{mg} / \mathrm{kg}$ body weight and (D) mice treated with compound K16 at the concentration of $50 \mathrm{mg} / \mathrm{kg}$ body weight. Glucose levels in the compound K16 group were lower than those of alloxan group after treatment of compound K16. Data are expressed as the mean \pm standard error $(\mathrm{n} \geq 2)$. ${ }^{*} \mathrm{P}<0.05,{ }^{* *} \mathrm{P}<0.01$ vs. alloxan. K16, (19R,23E)-5 $\beta, 19$-epoxy-19-methoxy-cucurbita-6,23,25-trien-3 $\beta$-o-10.

Analysis of blood glucose level and glucose tolerance. Blood glucose levels were measured weekly. Blood samples were collected from the tail of the animals following a fasting period of $16 \mathrm{~h}$. The glucose levels in the samples were measured with a glucometer. Glucose tolerance was determined by the intraperitoneal glucose tolerance test (IPGTT), which was performed at week 4 of treatment. Again, the animals were subjected to a fasting period of $16 \mathrm{~h}$, and blood samples were then collected from the tail before ( 0 time) and at 5, 15, 30, 60 and $120 \mathrm{~min}$ after intraperitoneal injection of glucose ( $1 \mathrm{mg} / \mathrm{kg}$ body weight). The glucose levels in the blood samples were measured by a glucometer. Area under the curve of glucose concentration vs. time plot was calculated using GraphPad Prism 5 software (GraphPad Software, Inc., La Jolla, CA, USA).

Analysis of serum cholesterol and triglyceride levels, and organ index. At the end of week 4, blood samples were collected by eyeball extirpating and the animals were sacrificed by cervical dislocation. Serum was isolated from the blood samples by centrifugation at 5,000 $\mathrm{x} g \mathrm{~min}^{-1}$ for $10 \mathrm{~min}$ and the levels of cholesterol and triglycerides in the serum were then measured with a cholesterol (CHO) and triglyceride (TG) kit (Beijing BHKT Clinical Reagent Co., Ltd., Beijing, China). The liver, kidney, spleen and skeletal muscle were removed from the animals. They were weighed, snap-frozen in liquid nitrogen and stored immediately at $-80^{\circ} \mathrm{C}$. The organ index was calculated as: Organ index = organ weight/body weight.

Reverse transcription-quantitative polymerase chain reaction $(R T-q P C R)$. RT-qPCR was performed to measure the expression levels of Glut4 and Ampka1 in the liver of mice from different treatment groups. Total RNA was extracted from the liver tissue of three mice from each group. Liver tissue $(20 \mathrm{mg}$ ) was ground in liquid nitrogen in a mortar and the total RNA was extracted from the tissue homogenate using TRIzol (Beijing Kang Century Biotechnology Co., Ltd., Beijing, China). RT-qPCR analysis was performed as described previously (12) using the ABI Prism 7900-HT Real-Time PCR System (Applied Biosystem; Thermo Fisher Scientific, Inc., Waltham, MA, USA). Primers used in the RT-qPCR were as follow: Glut4, 5'-CTTGGCTCCCTTCAGTTTGG-3' (forward), 5'-CTACCCAGCCACGTTGCATT-3' (reverse); Ampka1, 5'-AAGCCGACCCAATGACATCA-3' (forward) and 5'-CTTCCTTCGTACACGCAAAT-3' (reverse); $\beta$-actin, 5'-AGGCAAACCGTGAAAAGATG-3' (forward) and 5'-AGG CAAACCGTGAAAAGATG-3' (reverse). $\beta$-actin was used as an internal control and expression levels were calculated using the $\Delta \Delta \mathrm{Cq}$ method (13).

Western blot analyses. The expression levels of several key proteins involved in the insulin signaling pathway in the liver were analyzed by western blotting. Liver tissue was extracted in radioimmunoprecipitation assay cell lysis buffer (Cell Signaling Technology, Inc.) for $15 \mathrm{~min}$ on ice (12). Subsequently, the extract was briefly sonicated and then centrifuged at $12,280 \times \mathrm{g}$ for $15 \mathrm{~min}$ at $4^{\circ} \mathrm{C}$. The supernatant of the sample was retained and the protein concentration in the supernatant was measured by bicinchoninic acid assay. Aliquots of the supernatant containing total protein $(40 \mu \mathrm{g})$ was resolved in $10 \%$ SDS-polyacrylamide gel and the protein bands were then 
A

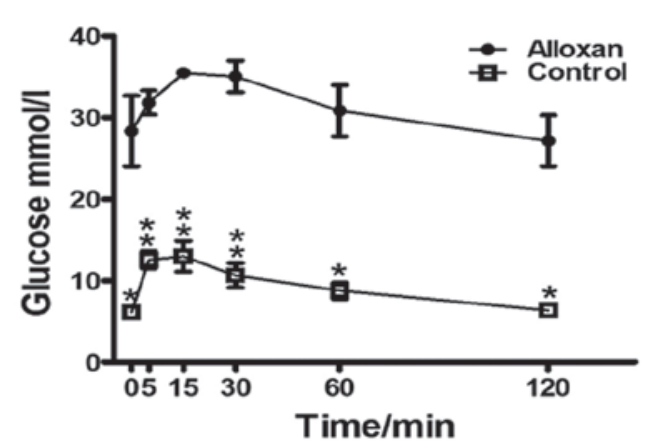

C

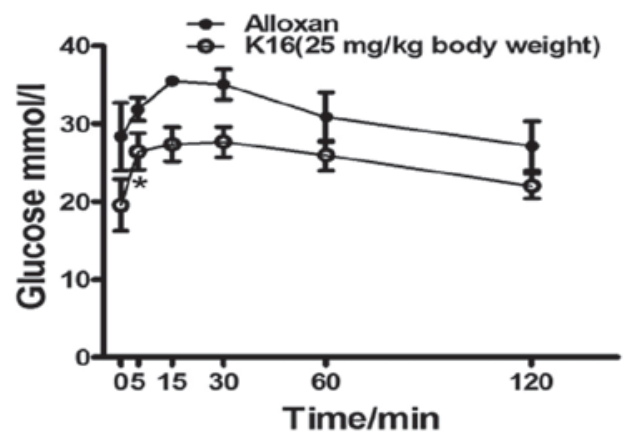

B

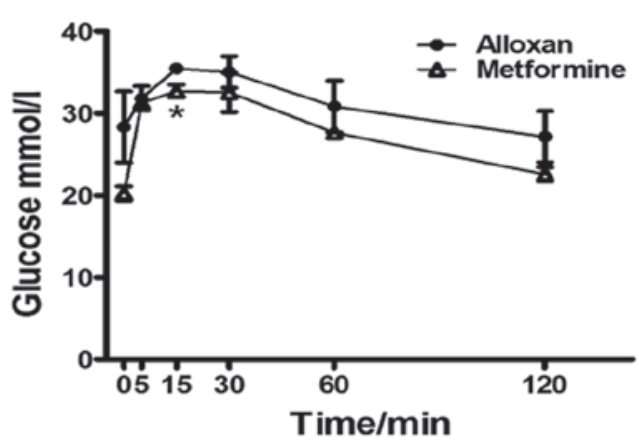

D

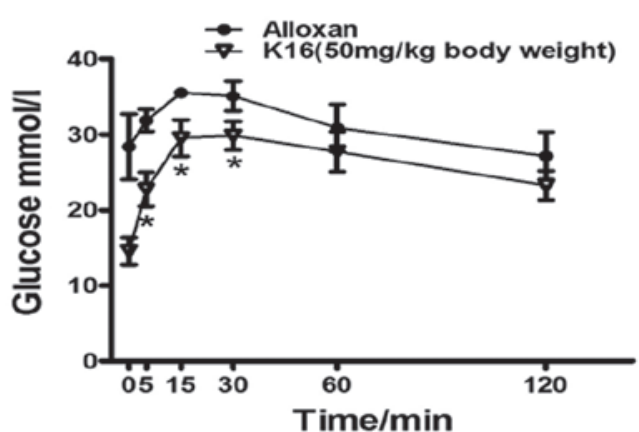

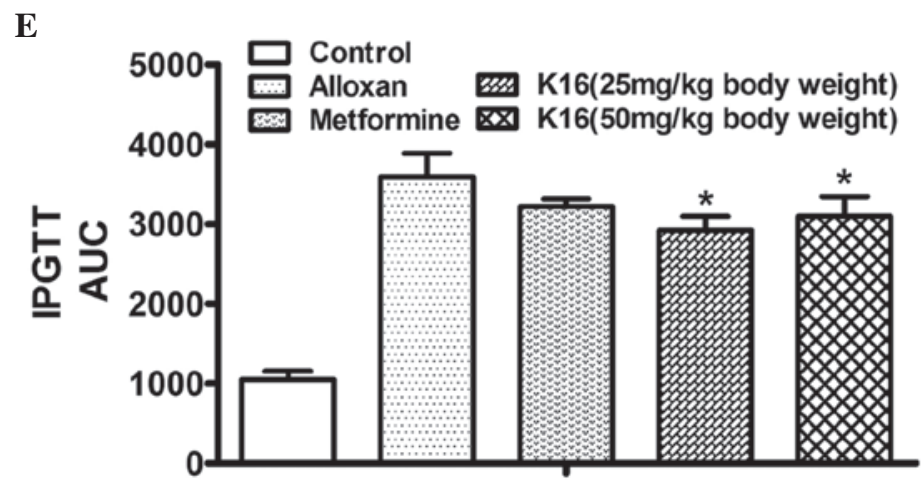

Figure 3. Effects of compound K16 on glucose tolerance. IPGTT was performed after a fasting period of 16 h. Time course of blood glucose concentrations during IPGTT was determined in the (A) control, (B) positive control (metformin), (C) mice treated with compound $\mathrm{K} 16$ at the concentration of $25 \mathrm{mg} / \mathrm{kg}$ body weight and (D) mice treated with compound K16 at the concentration of $50 \mathrm{mg} / \mathrm{kg}$ body weight. (E) AUC of IPGTT for each group. Data are expressed as the the mean \pm standard error $(\mathrm{n} \geq 2)$. ${ }^{*} \mathrm{P}<0.05,{ }^{* *} \mathrm{P}<0.01$ vs. alloxan. K16, (19R,23E)-5 $\beta, 19$-epoxy-19-methoxy-cucurbita-6,23,25-trien-3 $\beta$-o-10; IPGTT, intraperitoneal glucose tolerance test; AUC, area under curve.

transferred to a nitrocellulose membrane and blocked with $5 \%$ bovine serum albumin for $3 \mathrm{~h}$ at room temperature. Then the membranes were probed with the appropriate primary antibody overnight at $4^{\circ} \mathrm{C}$ followed by horseradish peroxidase conjugated secondary antibody (1:5,000; cat. nos. BL003A and BL001A; Biosharp Inc., Hefei, China) at room temperature for $2 \mathrm{~h}$. Primary antibodies were used at the following dilutions: IR (1:1,000); phosphorylated IR $(1: 1,000)$; IRS1 (1:1,000); GSK3 $\beta$ (1:1,000); p-GSK3 $\beta$ (1:500); phosphorylated Akt $(1: 1,000)$; and $\alpha$-tubulin $(1: 10,000)$. Positive signals of the blot were detected by an enhanced chemiluminescence assay (GE Healthcare Life Sciences, Chalfont, UK). The relative density of proteins was analyzed using ImageJ software (version 1.48; National Institutes of Health, Bethesda, MD, USA).
Statistical analyses. Data were analyzed by one-way analysis of variance followed by the Student-Newman-Keuls test performed with the SPSS software (version 16; SPSS, Inc., Chicago, IL, USA). Data are expressed as the mean \pm standard error and $\mathrm{P}<0.05$ was considered to indicate a statistically significant difference.

\section{Results}

Effect of compound K16 on blood glucose levels of alloxan-induced diabetic mice. The effect of compound K16 on the blood glucose levels of alloxan-induced diabetic mice was investigated by administering mice with compound K16 over a period of 4 weeks and monitoring the changes in the blood glucose levels each week. The blood glucose level of 

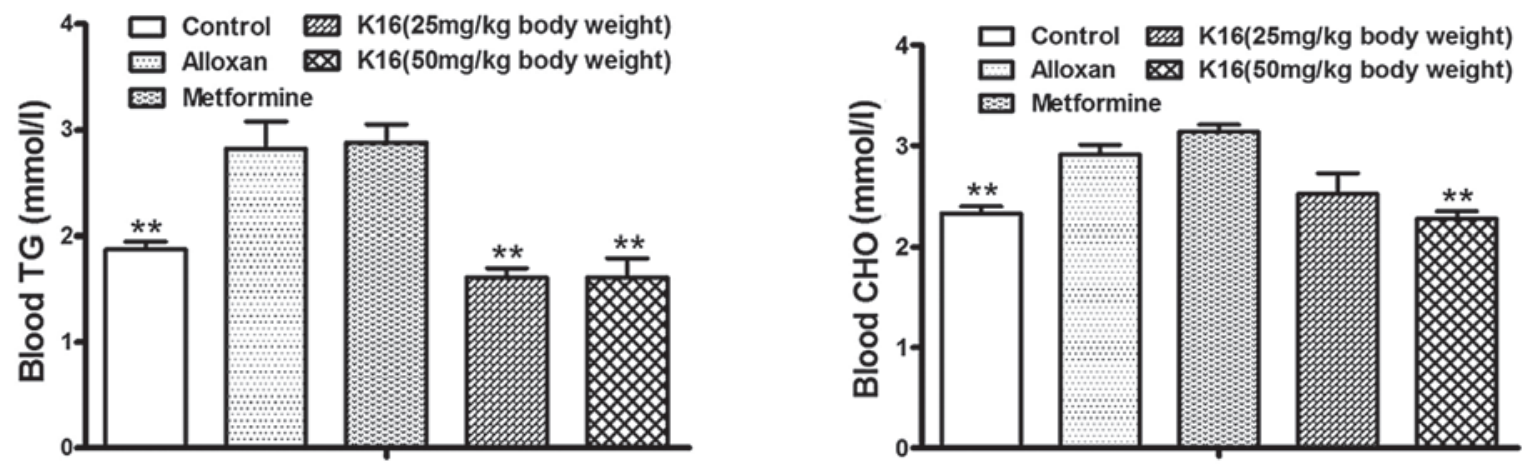

Figure 4. Effects of compound K16 on blood TG and CHO level in mice. Compound K16 decreased the CHO and TG levels. Data are expressed as the

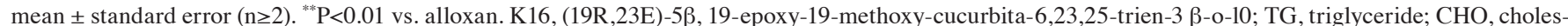
terol.

healthy control group was approximately one-third of the level of the alloxan-induced diabetic mice (alloxan group) and remained almost unchanged over the entire four weeks $(\mathrm{P}<0.05$; Fig. 2A). The blood glucose level of the metformine group was higher than that of alloxan group on the first week, but then decreased steadily to $\sim 70 \%$ of the level of the alloxan group by week 4 (Fig. 2B). The blood glucose levels of the two K16 groups were similar to that of the alloxan group week 1, however, the levels decreased over the following 3 weeks Although with the lower dosage of K16 the blood glucose level appeared to increase slightly at week 4 , the high dosage of K16 reduced the blood glucose level to $~ 50 \%$ the level of the alloxan group (Fig. 2C and D). These results demonstrated the positive antidiabetic activity of K16 regarding its ability to reduce blood glucose levels in drug-induced diabetic mice, although the extent of reduction did not reach the blood glucose level of healthy mice.

Compound $K 16$ improves the glucose tolerance of alloxan-induced diabetic mice. The effect of compound K16 on the blood glucose tolerance of diabetic mice was investigated by measuring the blood glucose level of the animal prior to and following administration of glucose at week 4, and subsequently monitoring the changes in blood glucose levels after 5, 10, 30, 60 and $120 \mathrm{~min}$. The blood glucose level of control mice was approximately one third the levels of alloxan-induced diabetic mice $(\mathrm{P}<0.05)$, and peaked at about $13 \mathrm{mmol} / \mathrm{l}$ after $15 \mathrm{~min}$, and then decreased to baseline level after 120 min (Fig. 3A). The blood glucose level of alloxan group followed essentially the same pattern, peaking at $15 \mathrm{~min}$, with a concentration of about $36 \mathrm{mmol} / \mathrm{l}$ and decreased to baseline levels after $120 \mathrm{~min}$. The blood glucose levels the metformine and two K16 groups over the entire $120 \mathrm{~min}$ were fairly similar; lower than the levels of the alloxan group (Fig. 3B-D). To compare the absolute change in the blood glucose over the entire 120 min period, the IPGTT AUC was calculated to demonstrate the total change in glucose. The results demonstrated that no significant difference in glucose tolerance was observed between the metformine treatment and the no treatment group (alloxan group; Fig. 3E). However, the AUC of the K16 groups was significantly reduced compared with the alloxan group $(\mathrm{P}<0.05)$, indicating that compound K16 improved the glucose tolerance in drug-induced diabetic

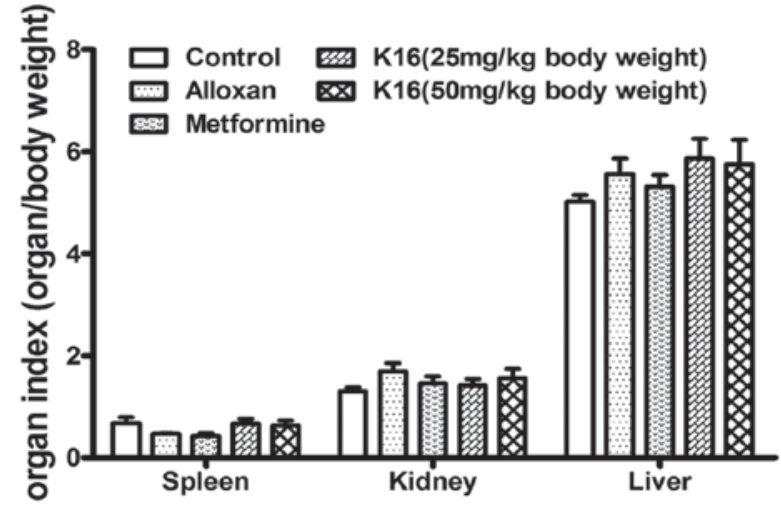

Figure 5. Effects of compound K16 on organ index in mice. There was no significant difference among the control, alloxan, metformine and K16 ( 25 or $50 \mathrm{mg} / \mathrm{kg}$ body weight) groups, which suggested K16 had no toxic effect on mice. Data are expressed as the mean \pm standard error $(n \geq 2)$. K16, (19R,23E)-5 $\beta, 19$-epoxy-19-methoxy-cucurbita-6,23,25-trien-3 $\beta$-o-10.

mice by eliminating exogenously administered glucose from the blood.

Compound K16 decreases serum lipids in alloxan-induced diabetic mice. Alloxan-induced diabetic mice treated with compound K16 over a period of 4 weeks were sacrificed at the end of the week 4. The TG levels of alloxan-induced diabetic mice were $\sim 50 \%$ higher than the level of control mice ( $\mathrm{P}<0.01$; Fig. 4A). The levels of serum TG in the two K16 groups were significantly decreased compared with the alloxan group $(\mathrm{P}<0.01)$, to levels that were even lower than the healthy control mice. As for serum $\mathrm{CHO}$ level, the alloxan group exhibited levels $\sim 30 \%$ higher than the healthy control group $(\mathrm{P}<0.01)$, with the metformine group yielding even higher levels (Fig. 4B), whereas the K16 groups exhibited reduced serum cholesterol levels compared with the alloxan group. However, only the high dosage $(50 \mathrm{mg} / \mathrm{kg}$ ) of compound $\mathrm{K} 16$ resulted in a significant reduction relative to the alloxan group $(\mathrm{P}<0.01$; Fig. 4B). These results indicated that compound K16 reduces the serum TG and CHO levels of drug-induced diabetic mice.

Effects of compound K16 on organ index. The effect of compound $\mathrm{K} 16$ on the organs of the mice was evaluated by determining the organ indexes (organ weight/body weight) 
A
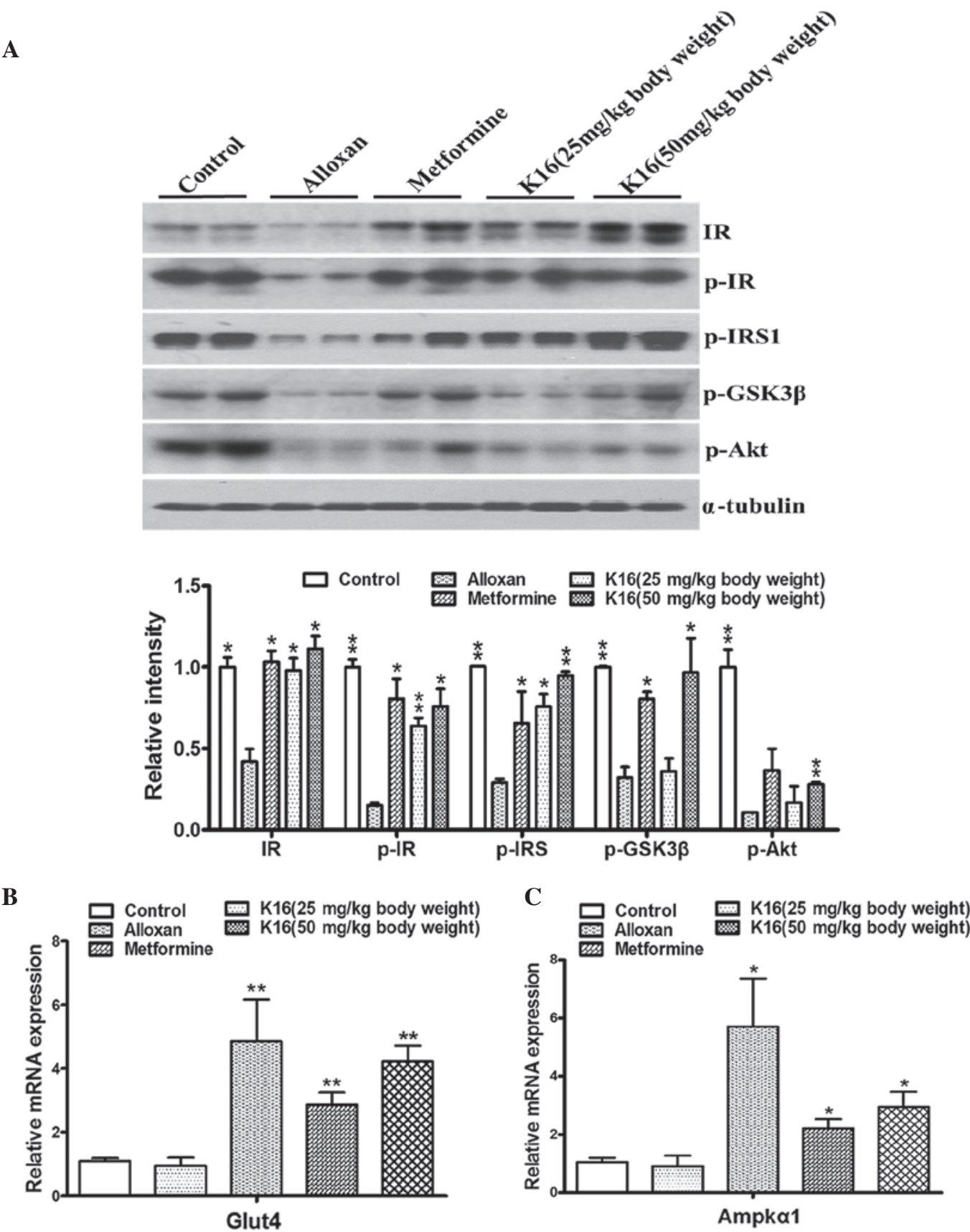

Figure 6. Changes in insulin signaling-associated proteins and genes in experimental mice. Compound K16 and metformine (positive control) increased (A) the levels of glycometabolism signaling-associated proteins and the mRNA levels of (B) Glut4 and (C) Ampka1 at different concentrations in mice, compared with alloxan treatment. $\alpha$-tubulin was used as a loading control for western blotting. All experiments were performed three times. Data are expressed as the mean \pm standard error $(\mathrm{n} \geq 2) .{ }^{*} \mathrm{P}<0.05,{ }^{* *} \mathrm{P}<0.01$ vs. alloxan. K16, $(19 \mathrm{R}, 23 \mathrm{E})-5 \beta, 19$-epoxy-19-methoxy-cucurbita-6,23,25-trien-3 $\beta$-o-10; IR, insulin receptor; p-, phosphorlyated; IRS, insulin receptor substrate; GSK3 $\beta$, gylcogen syntase kinase 3 $\beta$; Akt, Akt serine/threonine kinase; Glut4, glucose transporter type 4; Ampk $\alpha 1$, AMP-activated protein kinase $\alpha 1$.

of the spleen, liver and kidney following sacrifice of the animals at the end of the 4 -week treatment. Overall, there was no significant difference in the organ indexes among all the different groups (Fig. 5). This suggested that compound K16 exhibited no toxic effect on the animals.

Compound K16 upregulates the expression of glycometabolism-associated genes. The aforementioned experimental results indicated that compound K16 indeed exerted antidiabetic activity, as demonstrated by its ability to lower blood glucose level and to increase glucose tolerance in diabetic mice. Thus, to investigate the mechanisms associated with the antidiabetic activity of compound K16, the effect of the compound on the expression of genes or the activation of proteins that are involved in glycometabolism was analyzed. The expression/phosphorylation of IR, IRS1, GSK-3 $\beta$, Akt, Glut 4 and Ampk $\alpha 1$ were determined in the current study $(14,15)$. Compared with control mice, the phosphorylated protein levels of IR and IRS1 were significantly reduced in the alloxan group, however this reduction was significantly abolished in the K16 groups, at the low and high dosages (Fig. 6A). At the high dosage, compound K16 also significantly increased the 
levels of phosphorylated GSK-3 $\beta$ and Akt, compared with the levels in the alloxan group. Furthermore, RT-qPCR revealed that the mRNA levels of Glut4 and Ampk $\alpha 1$ were significantly increased when the mice were treated with metformine or compound K16 compared with the alloxan group (Fig. 6B). These results provided evidence that compound K16 mediated upregulation of certain genes involved in glycometabolism, and suggested that this may be part of the mechanism by which compound K16 exerts its antidiabetic activity.

\section{Discussion}

The present study examined the potential antidiabetic effect of compound K16, which was isolated from M. charantia, a plant that is well known for its medicinal properties against a variety of diseases, including diabetes. The data of the present study clearly demonstrated that compound K16 reduced blood glucose levels, improve glucose tolerance and reduced the levels of lipids (TG and CHO) in the serum of alloxan-induced diabetic mice. Furthermore, compound K16 appeared to perform better than the antidiabetic drug, metformine, with the high dosage (50 mg/kg compound K16) yielding marginally improved results compared with metformin, which were not statistically significant.

Previous studies have demonstrated that the application of M. charantia fruit extract for the treatment of diabetes resulted in a dose-dependent hypoglycemic effect $(4,16,17)$. A potential underlying mechanism of this anti-diabetic activity is thought to be the activation of Ampk, resulting in the upregulation of the Glut4 gene (18).

At the cellular level, a variety of natural polyphenols, including resveratrol, green tea polyphenols and polyphenols from Callistephus chinensis flower, have been demonstrated to activate Glut4 by activating the Ampk branch of the insulin-signaling pathway to stimulate glucose metabolism in fat and muscle tissues (19-22). However, high doses of resveratrol are less effective than low doses in the activation of Ampk and improvement of glucose utilization. Green tea polyphenols can relieve the condition of diabetes through modulating the expression of key proteins involved in the insulin signaling pathway, including IR, IRS1, Akt and GSK-3 $\beta(22,23)$. IR, IRS-1, Akt are predominantly activated by phosphorylation, and the data of the current study clearly demonstrated significant increases in the phosphorylated forms of these proteins in the alloxan-induced diabetic mice following treatment with compound K16, compared with no treatment (Fig. 6A). GSK-3 $\beta$ is a serine/threonine protein kinase, which was originally discovered for its involvement in regulating glycogen synthase $(23,24)$. Phosphorylation of GSK-3 $\beta$ is induced by activated Akt, which inhibits glycogen synthesis (25). A recent study by Yang et al (16) demonstrated that $M$. momordica exerts antidiabetic activities by decreasing the levels of the proinflammatory cytokines tumor necrosis factor- $\alpha$, interleukin 6 and $\mathrm{C}-\mathrm{C}$ motif chemokine ligand 2 , and inhibiting the nuclear factor- $\kappa \mathrm{B}(\mathrm{NF}-\kappa \mathrm{B})$ and $\mathrm{c}$-Jun $\mathrm{N}$-terminal kinase (JNK) pathways. These authors observed significant increases in the levels of phosphorylated IRS1 and Akt, and reduced a level of phosphorylated JNK in mice fed with a high fat diet and 3\% M. momordica compared to those fed with a high fat diet only. The data were consistent with the inhibitory effect on the phosphorylation of JNK and NF- $\mathrm{BB}$.
Activation of Ampk requires the presence of an additional subunit encoded by the gene Ampka1. Alloxan-induced diabetic mice treated with compound K16 demonstrated a significant increase in the level of Ampka1 transcripts compared with untreated mice (Fig. 6C), and this provided evidence that K16 exerts its antidiabetic activity through activation of Ampk $\alpha 1$. Furthermore, the transcript level of Glut4 was also significantly upregulated by compound K16. Glut4 is an insulin-regulated glucose transporter, which promotes glucose uptake into muscle tissue (7,26). Similarly, M. momordica-derived triterpenoids have been demonstrated to activate Ampka1 and increase Glut4 translocation to the plasma membrane, a mechanism that may be responsible for the enhanced elimination of glucose from insulin resistant models in vivo (6). The level of Glut4 in muscle tissues in Type 1 diabetes is substantially reduced. The expression of Glut 4 is regulated by the insulin signaling pathway through IRS1 and Ampk (27-30). An increased level of Glut4 allows more glucose to be transported into the cells, thus, the upregulation of Glut4 was consistent with the antidiabetic activity exhibited by compound K16.

In conclusion, the antidiabetic activity of K16 was demonstrated through its ability to reduce blood glucose level, increase glucose tolerance and reduce serum lipids in alloxan-induced diabetic mice model. In addition, insight into the underlying molecular mechanism by which compound K16 exerts its antidiabetic effects was revealed. However, as diabetes is a disease that requires long term and continuous medication in its treatment, further investigation involving longer animal trials is required to ascertain the potential of compound K16 as a therapeutic and to further understand the mechanism of its antidiabetic effect. However, the current findings represent a step forward in the search for an antidiabetic compound from natural sources that would be effective for treating diabetes, and illustrated the importance of M. momordica as an effective source for the search of natural antidiabetic drugs.

\section{Acknowledgements}

The work was financially supported by the program of Liaoning Excellent Talents in University (grant no. LETU\#LR2014001), the Projects of Liaoning Province Science and Technology Department (grant no. 2012226006) and the National Science Foundation of China to (grant nos. 81272333, 81001003 and 81273389). The authors thank Dr Alan K Chang (Liaoning University, Shenyang, China) for his contribution to the writing of the manuscript and Liaoning University of Traditional Chinese Medicine (Shenyang, China) for providing the experimental space for animal research.

\section{References}

1. World Health Organization, Diabetes Fact Sheet. World Health Organization, Geneva, 2015.

2. World Health Organization, Global health estimates: Deaths by cause, age, sex and country, 2000-2012. World Health Organization, Geneva, 2014.

3. Sharma BR, Kim HJ and Rhyu DY: Caulerpa lentillifera extract ameliorates insulin resistance and regulates glucose metabolism in $\mathrm{C} 57 \mathrm{BL} / \mathrm{KsJ}-\mathrm{db} / \mathrm{db}$ mice via PI3K/AKT signaling pathway in myocytes. J Transl Med 13: 62, 2015.

4. Grover JK and Yadav SP: Pharmacological actions and potential uses of Momordica charantia: A review. J Ethnopharmacol 93: 123-132, 2004. 
5. Zhu Y, Dong Y, Qian X, Cui F, Guo Q, Zhou X, Wang Y, Zhang Y and Xiong Z: Effect of superfine grinding on antidiabetic activity of bitter melon powder. Int J Mol Sci 13: 14203-14218, 2012.

6. Iseli TJ, Turner N, Zeng XY, Cooney GJ, Kraegen EW, Yao S, Ye Y, James DE and Ye JM: Activation of AMPK by bitter melon triterpenoids involves CaMKK $\beta$. PLoS One 8: e62309, 2013.

7. Tan MJ, Ye JM, Turner N, Hohnen-Behrens C, Ke CQ, Tang CP, Chen T, Weiss HC, Gesing ER, Rowland A, et al: Antidiabetic activities of triterpenoids isolated from bitter melon associated with activation of the AMPK pathway. Chem Biol 15: 263-273, 2008.

8. Chaturvedi P: Antidiabetic potentials of Momordica charantia: Multiple mechanisms behind the effects. J Med Food 15: 101-107, 2012.

9. Wang X, Sun W, Cao J, Qu H, Bi X and Zhao Y: Structures of new triterpenoids and cytotoxicity activities of the isolated major compounds from the fruit of Momordica charantia L. J Agric Food Chem 60: 3927-3933, 2012

10. Zeng K, He YN, Yang D, Cao JQ, Xia XC, Zhang SJ, Bi XL and Zhao YQ: New compounds from acid hydrolyzed products of the fruits of Momordica charantia L. and their inhibitory activity against protein tyrosine phosphatas 1B. Eur J Med Chem 81 176-180, 2014.

11. Li Y, Hamasaki T, Nakamichi N, Kashiwagi T, Komatsu T, Ye J, Teruya K, Abe M, Yan H, Kinjo T, et al: Suppressive effects of electrolyzed reduced water on alloxan-induced apoptosis and type 1 diabetes mellitus. Cytotechnology 63: 119-131, 2011.

12. Bi X, Fang W, Wang LS, Stoner GD and Yang W: Black raspberries inhibit intestinal tumorigenesis in apc1638+/- and Muc2-/- mouse models of colorectal cancer. Cancer Prev Res (Phila) 3: 1443-1450, 2010

13. Livak KJ and Schmittgen TD: Analysis of relative gene expression data using real-time quantitative PCR and the 2(-Delta Delta C(T)) Method. Methods 25: 402-408, 2001

14. Prabhakar V, Gupta D, Kanade P and Radhakrishnan M Diabetes-associated depression: The serotonergic system as a novel multifunctional target. Indian J Pharmacol 47: 4-10, 2015.

15. Alvim RO, Cheuhen MR, Machado SR, Sousa AG and Santos PC: General aspects of muscle glucose uptake. An Acad Bras Cienc 87: 351-368, 2015.

16. Yang SJ, Choi JM, Park SE, Rhee EJ, Lee WY, Oh KW, Park SW and Park CY: Preventive effects of bitter melon (Momordica charantia) against insulin resistance and diabetes are associated with the inhibition of NF-kappaB and JNK pathways in high-fat-fed OLETF rats. J Nutr Biochem 26: 234-240, 2015.

17. Lo HY, Ho TY, Li CC, Chen JC, Liu JJ and Hsiang CY: A novel insulin receptor-binding protein from Momordica charantia enhances glucose uptake and glucose clearance in vitro and in vivo through triggering insulin receptor signaling pathway. J Agric Food Chem 62: 8952-8961, 2014.
18. Zheng D, MacLean PS, Pohnert SC, Knight JB, Olson AL, Winder WW and Dohm GL: Regulation of muscle GLUT-4 transcription by AMP-activated protein kinase. J Appl Physiol (1985) 91: 1073-1083, 2001

19. Penumathsa SV, Thirunavukkarasu M, Zhan L, Maulik G, Menon VP, Bagchi D and Maulik N: Resveratrol enhances GLUT-4 translocation to the caveolar lipid raft fractions through AMPK/Akt/eNOS signalling pathway in diabetic myocardium. J Cell Mol Med 12: 2350-2361, 2008.

20. Turan B, Tuncay E and Vassort G: Resveratrol and diabetic cardiac function: Focus on recent in vitro and in vivo studies. J Bioenerg Biomembr 44: 281-296, 2012.

21. Dasgupta B and Milbrandt J: Resveratrol stimulates AMP kinase activity in neurons. Proc Natl Acad Sci USA 104: 7217-7222, 2007.

22. Wang X, Tian J, Jiang J, Li L, Ying X, Tian H and Nie M: Effects of green tea or green tea extract on insulin sensitivity and glycaemic control in populations at risk of type 2 diabetes mellitus: A systematic review and meta-analysis of randomised controlled trials. J Hum Nutr Diet 27: 501-512, 2014.

23. Ozcan U, Cao Q, Yilmaz E, Lee AH, Iwakoshi NN, Ozdelen E, Tuncman G, Görgün C, Glimcher LH and Hotamisligil GS: Endoplasmic reticulum stress links obesity, insulin action, and type 2 diabetes. Science 306: 457-461, 2004.

24. Embi N, Rylatt DB and Cohen P: Glycogen synthase kinase-3 from rabbit skeletal muscle. Separation from cyclic-AMP-dependent protein kinase and phosphorylase kinase. Eur J Biochem 107: 519-527, 1980.

25. Souto Padron de Figueiredo A, Salmon AB, Bruno F, Jimenez F, Martinez HG, Halade GV, Ahuja SS, Clark RA, DeFronzo RA, Abboud HE and El Jamali A: Nox 2 mediates skeletal muscle insulin resistance induced by a high-fat diet. J Biol Chem 290: 13427-13439, 2015

26. Shih CC, Lin CH, Lin WL and Wu JB: Momordica charantia extract on insulin resistance and the skeletal muscle GLUT4 protein in fructose-fed rats. J Ethnopharmacol 123: 82-90, 2009.

27. Huang S and Czech MP: The GLUT4 glucose transporter. Cell Metab 5: 237-252, 2007

28. Cheng HL, Huang HK, Chang CI, Tsai CP and Chou CH: A cell-based screening identifies compounds from the stem of Momordica charantia that overcome insulin resistance and activate AMP-activated protein kinase. J Agric Food Chem 56: 6835-6843, 2008

29. McCarty MF: Does bitter melon contain an activator of AMP-activated kinase? Med Hypotheses 63: 340-343, 2004.

30. Jiang Q, Takemori AE, Sultana M, Portoghese PS, Bowen WD, Mosberg HI and Porreca F: Differential antagonism of opioid delta antinociception by [D-Ala2, Leu5, Cys6]enkephalin and naltrindole 5'-isothiocyanate: Evidence for delta receptor subtypes. J Pharmacol Exp Ther 257: 1069-1075, 1991. 